\title{
Inferring the high velocity of landslides in Valles Marineris on Mars from morphological analysis
}

\author{
Paolo Mazzanti ${ }^{1}$, Fabio Vittorio De Blasio ${ }^{1,2^{*}}$, Camilla Di Bastiano ${ }^{1}$ and Francesca Bozzano ${ }^{1}$
}

\begin{abstract}
The flow characteristics and velocities of three landslides in Valles Marineris on Mars are investigated using detailed morphological analyses of high-resolution images and dynamical calculations based on the run-up and curvature of the landslide deposits. The morphologies of the landslides are described, especially concerning those characteristics that can provide information on the dynamics and velocity. The long runout and estimated high velocities, often exceeding $100 \mathrm{~m} / \mathrm{s}$, confirm a low basal friction experienced by these landslides. Because subaqueous landslides on Earth exhibit reduced friction, we explore the scenario of sub-lacustrine failures, but find little support to this hypothesis. The environmental conditions that better explain the low friction and the presence of longitudinal furrows suggest an aerial environment with a basal soft and naturally lubricating medium on which friction diminished gradually; in this perspective, ice is the most promising candidate.
\end{abstract}

Keywords: Mars, Landslide dynamics, Valles Marineris, Melas Chasma, Mars climate, Basal friction

\section{Introduction}

Large, ancient landslides have been recognized on Mars since the Viking missions (Lucchitta 1979, 1987; Shaller 1991). More recently, comparative analysis of different landslides was made possible based on updated data and images with better resolution, also allowing some quantitative studies of slope stability (e.g., Schulz 2002; Harrison and Grimm 2003; Quantin et al. 2004a, b; Soukhovitskaya and Manga 2006; Lajeunesse et al. 2006; Bigot-Cormier and Montgomery 2007; Bulmer 2012; Brunetti et al. 2014). Several landslides cluster in the Valles Marineris (also VM, hereafter), a system of valleys stretching W-E along the equator that had a complex history of extensional tectonics and collapse (e.g., Schultz 1998; Hauber et al. 2010). Massive and long landslides were triggered as a consequence of gravitative instability of the relief higher than $6000 \mathrm{~m}$ combined with steep $\left(>20^{\circ}\right)$ slope (Crosta et al., 2014).

\footnotetext{
* Correspondence: fvblasio@geologi.uio.no

"Department of Earth Sciences, University of Rome "Sapienza", Piazzale Aldo Moro 5, 00185 Rome, Italy

${ }^{2}$ Present address: Department of Earth and Environmental Sciences,

University of Milano "Bicocca", Piazza della Scienza 4, 20126 Milan, Italy
}

There are several statistical and morphological works on landslides in VM. Comparatively fewer studies have been dedicated to the dynamics, and the velocity at which these catastrophic events took place remains largely unknown. Analogical simulations (e.g., Lajeunesse et al. 2006) and numerical simulations of landslides in Valles Marineris (Harrison and Grimm 2003; Lucas and Mangeney 2007; Lucas et al. 2011; De Blasio 2011a) attempt at simulating the velocity during the flow and may provide indications on the rheology and geomechanics but, strictly speaking, they are not measurements of the velocity.

In this work, we study the geomorphological indicators of the dynamics and velocity reached by landslides in VM during their flow. Based on images from HRSC (High-Resolution Stereo Camera on board Mars Express, Neukum et al. 2004; Kim et al. 2013), THEMIS on board Mars Odyssey (Christensen et al. 2004a, b) and Context CTX camera on board Mars Reconaissance Orbiter (Malin et al. 2007), we examine thoroughly the morphology of three landslides. Figure 1 shows an overview of the landslides considered in this study and Table 1 presents relevant data. The first landslide is located in Melas Chasma and the other two (Ophir Labes and
Springer

(c) 2016 Mazzanti et al. Open Access This article is distributed under the terms of the Creative Commons Attribution 4.0 International License (http://creativecommons.org/licenses/by/4.0/), which permits unrestricted use, distribution, and reproduction in any medium, provided you give appropriate credit to the original author(s) and the source, provide a link to the Creative Commons license, and indicate if changes were made. 


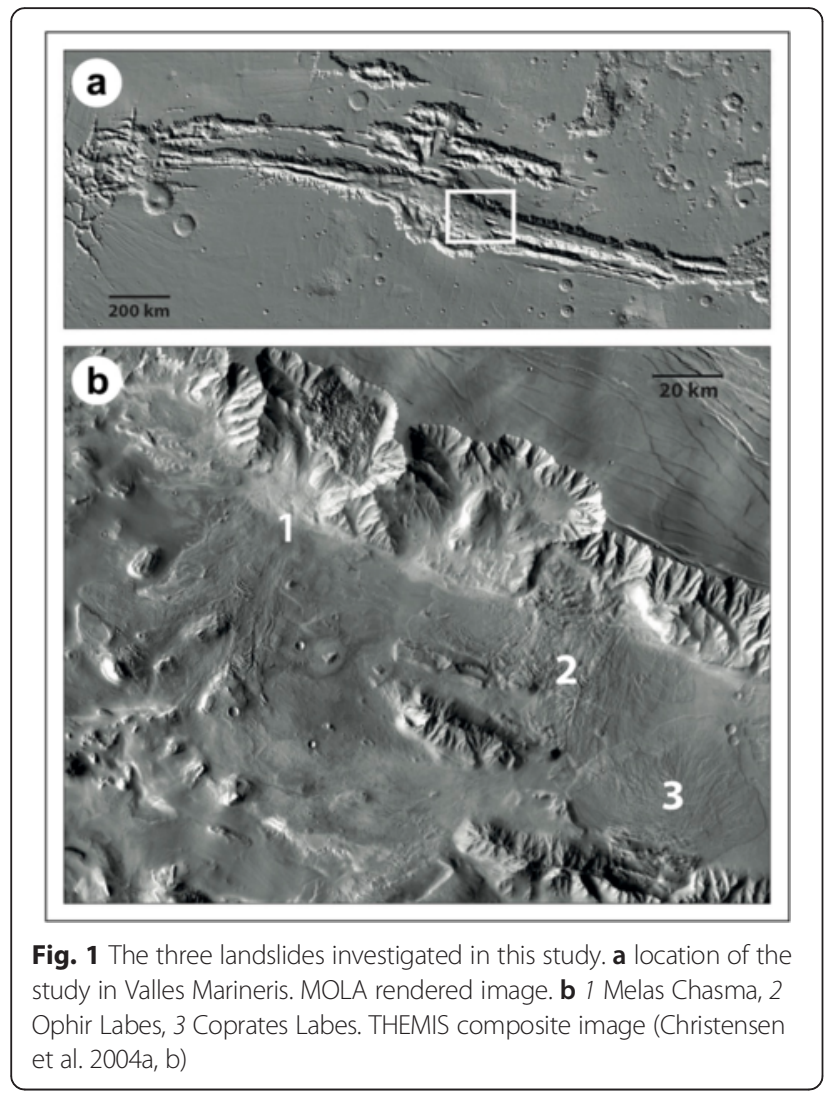

Coprates Labes) at the boundary between Melas and Coprates Chasma. One of the main reasons to choose these particular landslides is that Melas Chasma and Ophir Labes landslides have come across natural obstacles along their path, which allows for an estimate of the velocity by the run-up and runout measurements, while Coprates Labes landslide traveled unconfined on a completely flat area. In spite of the variety of landslides on Mars, these three typologies are representative of the key landslide morphologies for VM.

The critical motivation for determining landslide dynamics in Valles Marineris is that this kind of information may aid inferring the climatological conditions at the moment of flow. Mars has unquestionably been wetter and icier than today during part of its history (e.g., Baker 2001; Kargel 2004; Squyres et al. 2004; Carr 2006; Fairén 2010; Parker et al. 2010). Whereas the surface of the lowlands in the northern hemisphere exhibits widespread indications of ice at higher latitudes (Mouginot et al. 2012), only more recently has it been suggested that glacial conditions might have been achieved in the equatorial regions during some episodes of Mars Hesperian-Amazonian history (Head and Marchant 2003; Murray et al. 2005; Fueten et al. 2011; De Blasio 2011a; Gourronc et al. 2014). Thus, different lines of evidence suggest that VM has been filled for a long period by subsurface or exposed ice (De Blasio 2011a; Gourronc et al. 2014) or a lake (Ori et al. 2000; Harrison and Chapman 2008, 2010; Lucchitta 2009; Metz et al. 2009; Flahaut et al. 2010; Lucchitta 2010; Sowe et al. 2011; Warner et al. 2013; Fueten et al. 2014). This work explores landslide morphologies also with the objective of providing more independent data on their depositional environment.

\section{Detailed description of the landslides}

A detailed morphological analysis of the landslides has been carried out with a specific focus on features related to the dynamics of the mass flow. The study is based especially on THEMIS, MOLA, CTX, HiRISE, and HRSC images and digital elevation models from MOLA and HRSC data.

The three landslides (Fig. 1 and Table 1) have a similar volume ranging from $10^{11}$ to $10^{12} \mathrm{~m}^{3}$ and comparable deposition areas of the order $2000 \mathrm{~km}^{2}$. Landslide volumes were estimated by Quantin et al. (2004a) as $376 \mathrm{~km}^{3}$, $458 \mathrm{~km}^{3}$, and $346 \mathrm{~km}^{3}$, respectively. However, being based on MOLA profiles, these volume estimates are uncertain. Accurate geomorphological descriptions of some of the landslides in Valles Marineris and their features have been published by several researchers, especially Lucchitta (1987), Shaller (1991), Quantin et al. (2004a), and Bulmer (2012). Here, however, we focus only on some peculiar morphological features that can elucidate the dynamics of flow and the emplacement velocity.

Table 1 Key features of the three investigated landslides

\begin{tabular}{llll}
\hline Features & Melas Chasma & Ophir Labes & Coprates Labes \\
\hline Runout $(\mathrm{km})$ & $100-120$ & $40 / 60 / 65$ & 65 \\
Deposit area $\left(\mathrm{km}^{2}\right)$ & 2500 & 2700 & 1900 \\
Source area $\left(\mathrm{km}^{2}\right)$ & 70 & 60 & 330 \\
Fall height $(\mathrm{km})$ & 9 & 6 & 4.5 \\
Volume, Quantin et al. (2004a) $\left(\mathrm{km}^{3}\right)$ & 376 & 458 & 346 \\
Fahrböschung & 0.075 & 0.120 & 0.069 \\
\hline
\end{tabular}

We list the runout distance, the area of the deposit and of the source, the maximum fall height, the estimated volume, and the Fahrböschung (i.e., the fall height divided by the runout) 
Note that with an estimated age of 1 Gy as reported by Quantin et al. (2004b), Melas Chasma would be the most ancient of the three landslides, while Coprates Labes and Ophir Labes would date to 400 and $150 \mathrm{My}$, respectively. However, because the CTX and HRSC imagery indicates that Coprates Labes has run on top of the landslide deposit of Ophir Labes, it must be more recent. We deduce that, although dating with crater counting has provided fundamental clues on the age of Martian surfaces (Neukum et al. 2001), the application to small surfaces may be problematic and should be taken with care (e.g., Kerr 2006).

\section{Melas Chasma landslide}

Figure 2 shows the morphological map of Melas Chasma landslide whose scar and depositional area are extensively described below.

\section{Scar area}

By using topographic, optical, and thermal inertial data (Appendix 1), the scar of Melas Chasma landslide can be divided into four principal portions (1 to 4 in Fig. $3 \mathrm{a}-\mathrm{c}$ ):

1) A steep $\left(26^{\circ}-35^{\circ}\right)$ detachment niche about $30 \mathrm{~km}$ wide and $5 \mathrm{~km}$ long at an elevation ranging approximately from 4000 to $700 \mathrm{~m}$ above datum. In the upper part, an outcropping rock layer can be interpreted by high thermal inertia data whereas, in the lower part, talus-like deposits are inferred by low values of thermal inertia.
2) A 15 -km-long, $500 \mathrm{~km}^{2}$, hummocky deposit at reference elevation of about 500-700 m, obliterating a typical spur and gully morphology (Fig. 3a). The thermal inertia pattern, characterized by alternating low and high values, is consistent with the presence of an irregular combination of blocks and fine material.

3) A secondary scar about $30^{\circ}$ steep and $3 \mathrm{~km}$ long between heights of 200-600 m, characterized by high values of thermal inertia that can be interpreted as exposed bare rock as remnants of the sliding surface.

4) A steep region with erosion cones and grooves characterized by high values of thermal inertia, also interpreted as the remnant of the sliding surface.

\section{Deposit}

The Melas Chasma landslide deposit has a length from the base of the VM to the last portion of the deposit of $70 \mathrm{~km}$, i.e., a runout of about $120 \mathrm{~km}$ from the upper scar, for an estimated deposition area of $2500 \mathrm{~km}^{2}$. The maximum landslide thickness, reached at the center portion, ranges between 80 and $200 \mathrm{~m}$ (see Appendix 1 for thickness determination). It is worth noticing that the landslide morphology shows evidences of several emplacement phases (see for example the red dashed line in Fig. 2). Furthermore, a notable topographic low in correspondence with the landslide deposit can be identified, suggesting a laterally confined emplacement of the sliding mass.

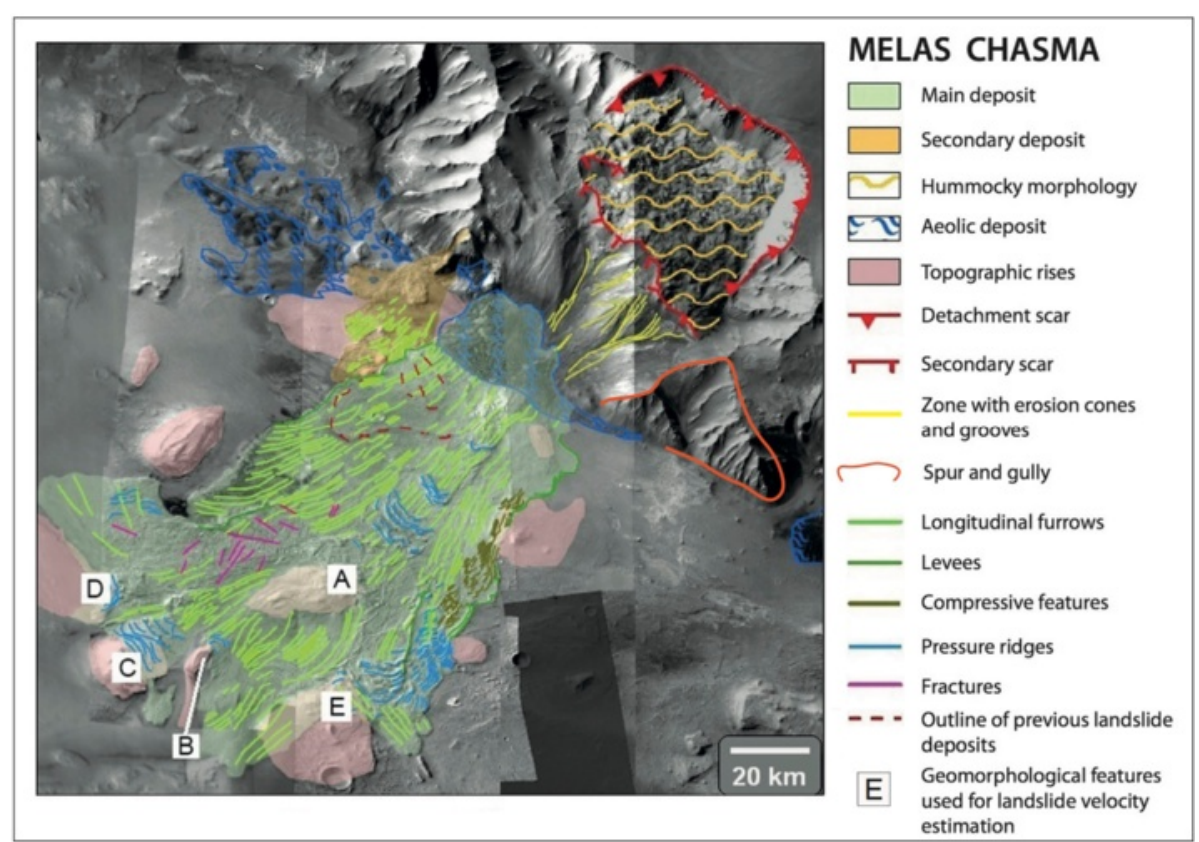

Fig. 2 Geomorphological map of the Melas Chasma landslide with indicated the most important features of the terrain. The map has been built based both on general examination of the THEMIS images, and on scrutiny of the HRSC images at the detail of $10 \mathrm{~m}$ per pixel. Points A-E indicate the positions where velocities have been estimated (see Table 2) 


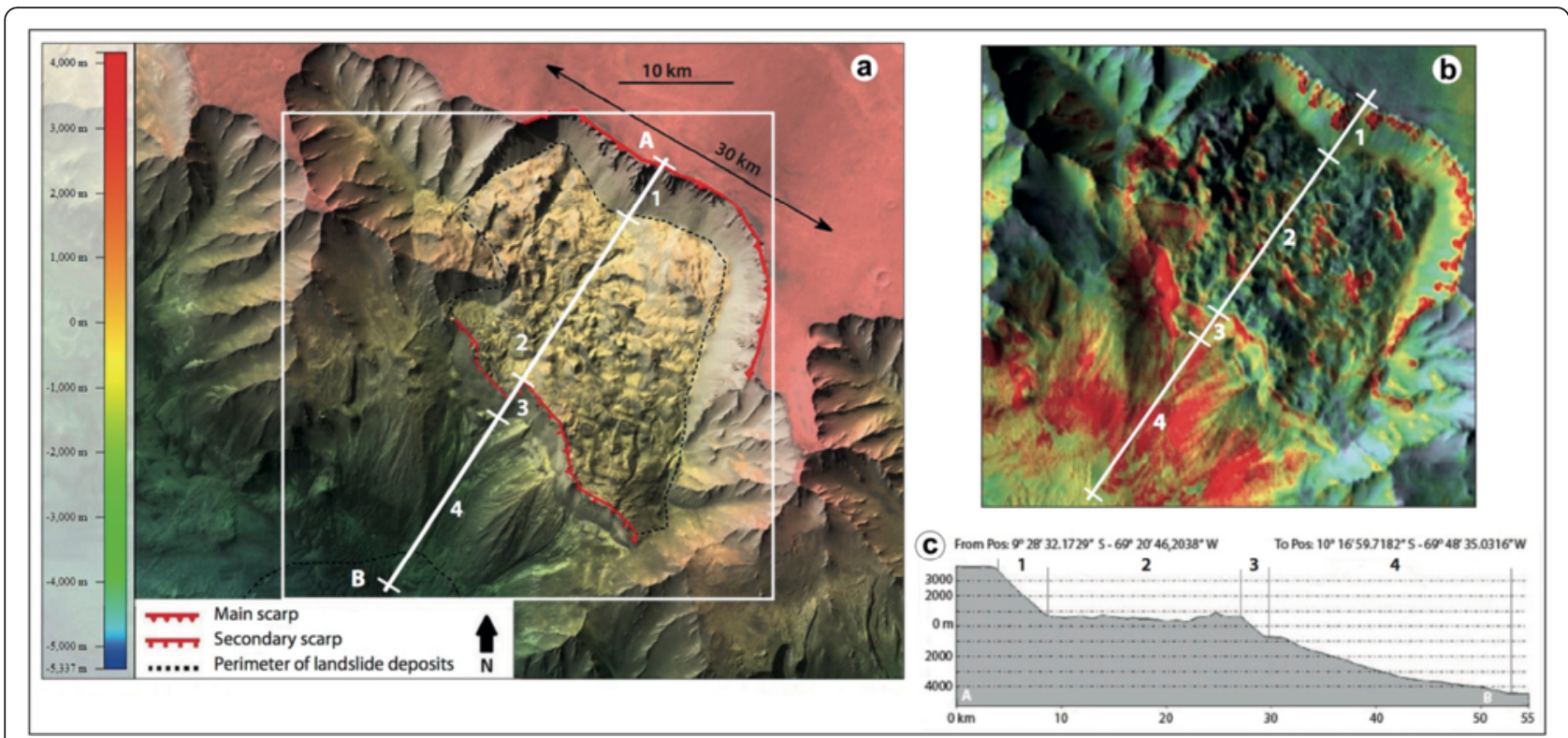

Fig. 3 Details of the Melas Chasma landslide scar area: a map of the scar area with indication of the cross section in c (white lines) and scar portions (white numbers from 1 to 4); $\mathbf{b}$ THEMIS image showing the difference between diurnal and nighttime thermal emission in the upper part of the Melas Chasma landslide, in red high thermal inertia and in green low thermal inertia. c Cross section of the scar area corresponding to the white line in a

The following peculiar morphologies have been investigated due to their implication on the landslide kinematics:

- Longitudinal furrows that we use as markers to infer the local direction of the movement (Fig. 2) appear in the images with spacing of the order of some decameters. Curved furrows can be identified in the western boundary, suggesting for a changing trajectory during emplacement

- Transversal ridges resulting from the impact of the landslide mass with some mounds: A, B, C, D, and E in Fig. 2.

Specifically, mound A, which is located about $45 \mathrm{~km}$ from the base of the valley, partly intercepted the frontal part of the moving mass, where three different systems of 100-300 m high pressure ridges were generated at increasing distance from the foot. Mound A also split the landslide mass in a westward and eastward part. However, a smaller portion has been capable of overtopping and then flowing past the mound, as shown by the presence of the deposit on the lee side of the mound. Here, flow lines indicate a direction in continuity with the one before impact (Fig. 4). The disappearance of flow lines followed by their new occurrence on the lee side may be puzzling, but a similar feature can be observed in the Alaskan Sherman landslide, where the western side of the rock avalanche has flowed past a spur (Shreve 1966).

Mound D stopped the western part of the mass that reached its top, where more pressure ridges were developed. Other pressure ridges are observed in correspondence with mounds B, C, and E (Fig. 2).

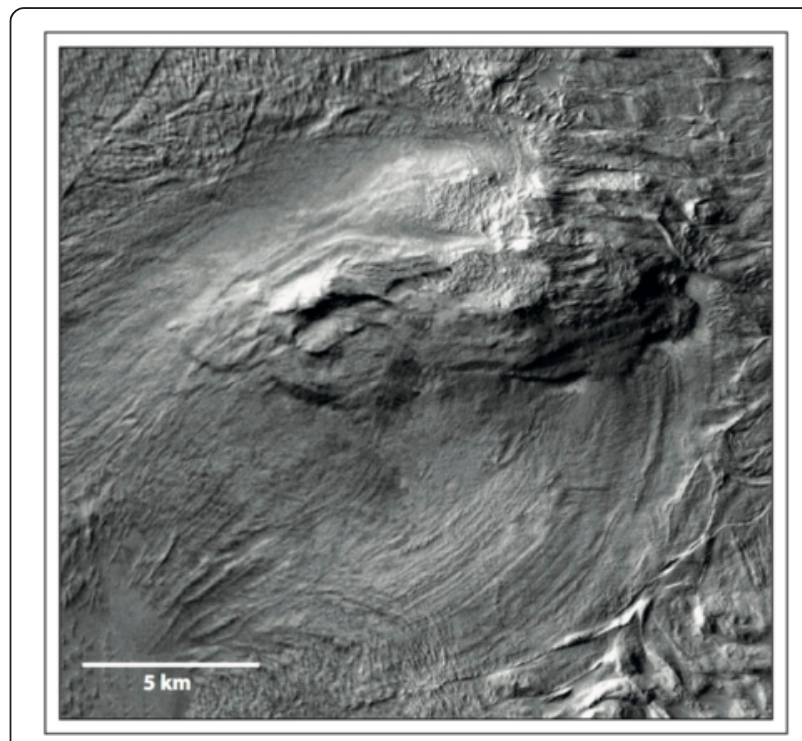

Fig. 4 Details of the mound A (Fig. 2) in the Melas Chasma landslide deposition area showing the disappearance of flow lines followed by their new occurrence on the lee side. Image HRSC H3195_0000_ND4 


\section{Ophir Labes landslide \\ Scar area}

The Ophir Labes landslide (Fig. 5) took origin from two main adjacent scars: the larger western scar and the eastern scar (Ophir Labes (A) and Ophir Labes (B), respectively in Fig. 6). Furthermore, an additional scar overlapping Ophir Labes (A) is hypothesized based on the OL-C deposit (Fig. 5). Ophir Labes A scar exhibits a concave niche about $22 \mathrm{~km}$ wide filled with hummocky deposit similar, albeit smoother, to that of Melas Chasma, while Ophir Labes B scar is narrower (about $14 \mathrm{~km}$ ) and lower in altitude.

\section{Deposit}

The Ophir Labes landslide path was severely affected by two ridges parallel to the main valley axis ( $\mathrm{F}-\mathrm{G}$ and $\mathrm{H}$ in Fig. 5). These ridges are, respectively, 1300 and $2700 \mathrm{~m}$ higher than the base level of Melas Chasma. Furthermore, the combination of different sources made the deposit structure even more complex. Specifically, the three main deposit units can be classified as follows:

- The central deposit (OL-A in Fig. 5), originating mainly from the Ophir Labes A scar, traveled southward following a straight path and then impacted with topographic rises F-G. A part of the frontal material spilled over the mound between F and G, thus depositing a residual spillover deposit beyond the mound. A smaller portion of OL-A continued traveling unperturbed on a gently sloping area, thus developing longitudinal furrows, before impacting against another mound in $\mathrm{H}$ and coming to rest on its top.

- The eastern deposit (OL-B on Fig. 5), originating from the Ophir Labes B scar, traveled unimpeded on the basal floor developing neat longitudinal furrows and reached the longest runout distance recorded for Ophir Labes landslide. The unconstrained nature of this flow is confirmed by the absence of transversal pressure ridges and by the thin front, only about $25 \mathrm{~m}$ thick (thickness is measured at the sides, as the central part is overridden by the Coprates Labes landslide).

- The western deposit (OL-C of Fig. 5), originating from Ophir Labes A scar, impacted tangentially against the mound to the west of point $G$, thus changing direction with respect to the main axis of the scar and coming to rest after about 30-35 km of travel at the basal level of VM. The deposit (300 to $350 \mathrm{~m}$ thick) exhibits curved longitudinal furrows indicating the change of direction of the landslide mass during the movement. The collision has shaped a series of 12 to $15 \mathrm{~km}$-long pressure ridges reminiscent of reflecting waves from a wall (Figs. 5 and 6). The particularity of these ridges is that in the distal part, they are partly longitudinal to the

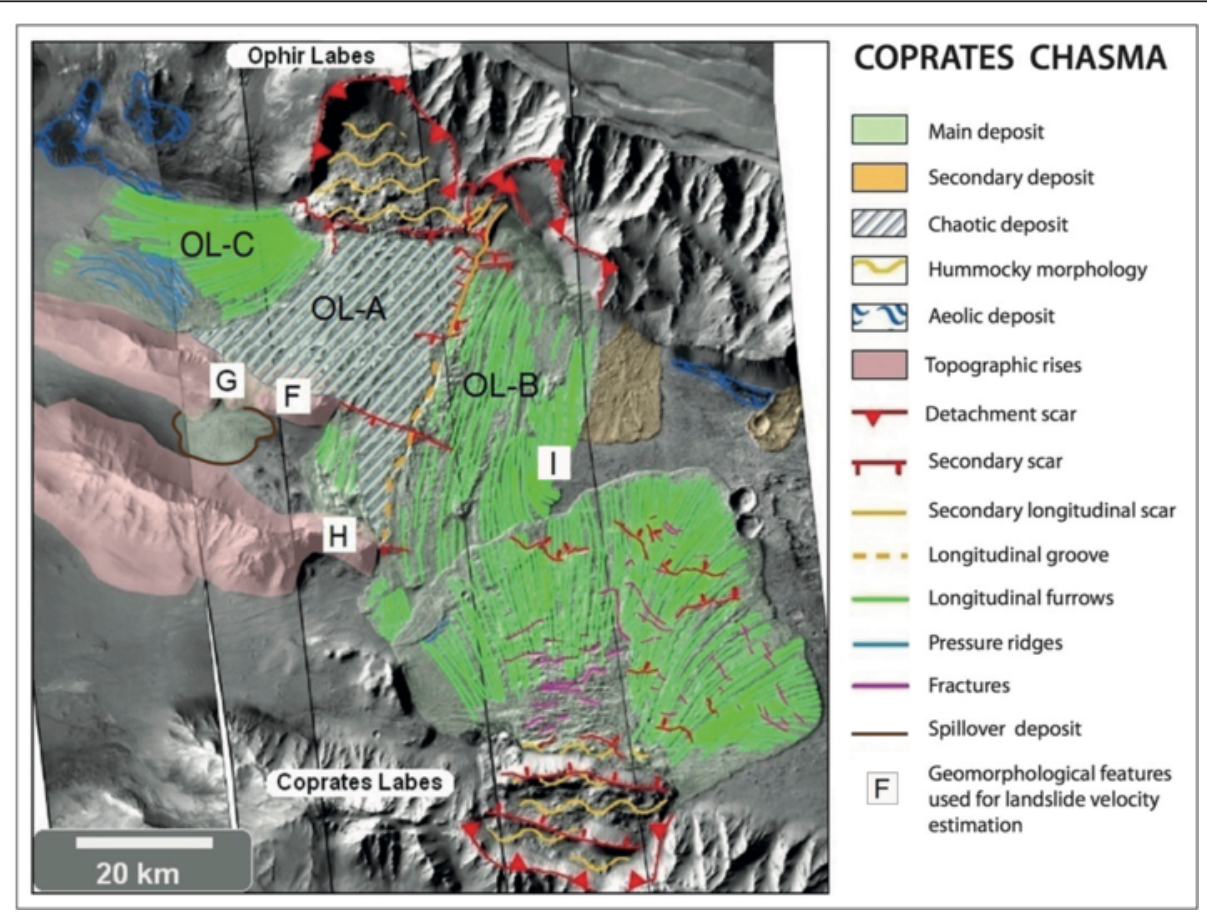

Fig. 5 Geomorphological map of the Ophir Labes and Coprates Labes landslides located at the boundary between Melas-Coprates Chasmata of VM, with indicated the most important features of the terrain. The map has been built based both on general examination of the THEMIS images, and on scrutiny of the HRSC images at the detail of $10 \mathrm{~m}$ per pixel Points F-I indicate the positions where velocities have been estimated (see Table 2) 


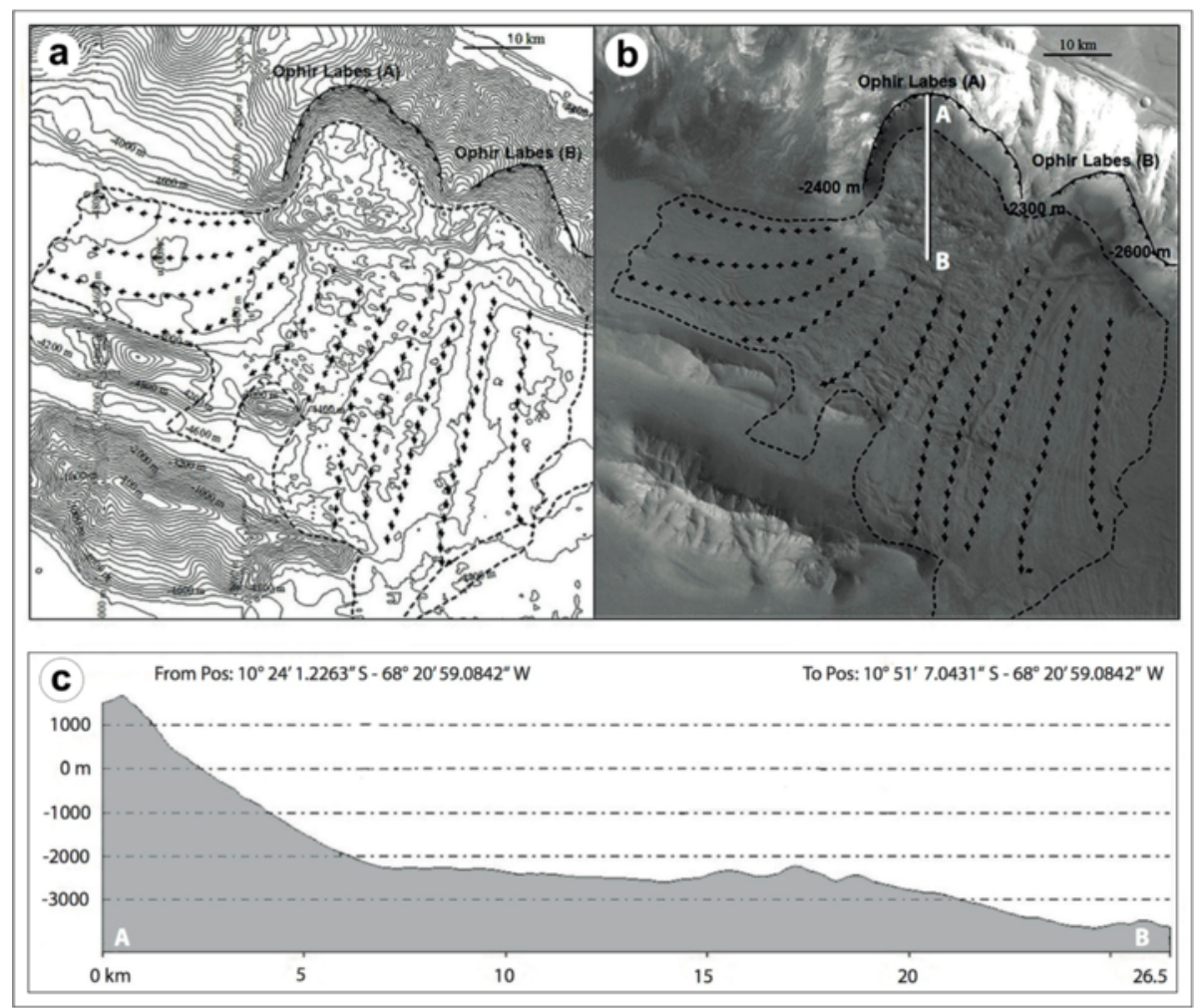

Fig. 6 a Elevation maps of the Ophir Labes landslide. b HRSC image (H2039_0000_ND4) of the same area. c Elevation through the section (a-b)

flow direction. This feature should be compared with the Melas Chasma landslide (Fig. 2), where the head-on directions of impact with the mounds resulted in pressure ridges perpendicular to the flow direction.

\section{Coprates Labes landslide \\ Scar}

The Coprates Labes (CL) landslide developed from one of the central ridges of VM. Because such ridges are essentially linear and have narrow features, the scar of CL did not develop the characteristic bowl-like shape of most landslides of VM (Figs. 5 and 7). The detachment niche, about $20 \mathrm{~km}$ long, is made up of three separate, parallel scars, resembling the typical landforms know on Earth as "Toreva blocks" (Reiche 1937; Lucas et al. 2011) also recognized in the Socompa Volcano (Kelfoun and Druitt 2005).

The main scarp closer to the ridge has a slope angle between $28^{\circ}$ and $30^{\circ}$ and average elevation of $3000 \mathrm{~m}$ above the basal level of VM, while the two secondary scarps amount to half that height. This landslide has been described earlier in some detail and also simulated numerically (Harrison and Grimm 2003; Quantin et al. 2004a; Lucas et al. 2011).

\section{Deposit}

Owing to the absence of obstacles along the path and the straight scar, the deposit of CL is among the most regular and symmetric of all the VM landslides. The deposits open in a rhomboidal 43-km-long fan that thins out as a function of the distance from the ridge, ranging from a thickness of $450 \mathrm{~m}$ in the central part to 50$80 \mathrm{~m}$ at the edges. The distance between the longitudinal furrows increases from the scar to the distal region. The deposit also exhibits small scarps along the path, subperpendicular to the flow direction. Notably, the western edge of the landslide has slid on top of the deposit of Ophir Labes, demonstrating that $\mathrm{CL}$ is younger than OL. At the superposition region, there is a series of pressure ridges that indicate a greater hindrance for $\mathrm{CL}$ to travel on the previous deposit in comparison to the bottom of VM (Fig. 5). The two impact craters in the eastern part of the deposit of approximate diameter $3 \mathrm{~km}$, being younger than the landslide, cannot thus be used for the assessment of the flow dynamics. 


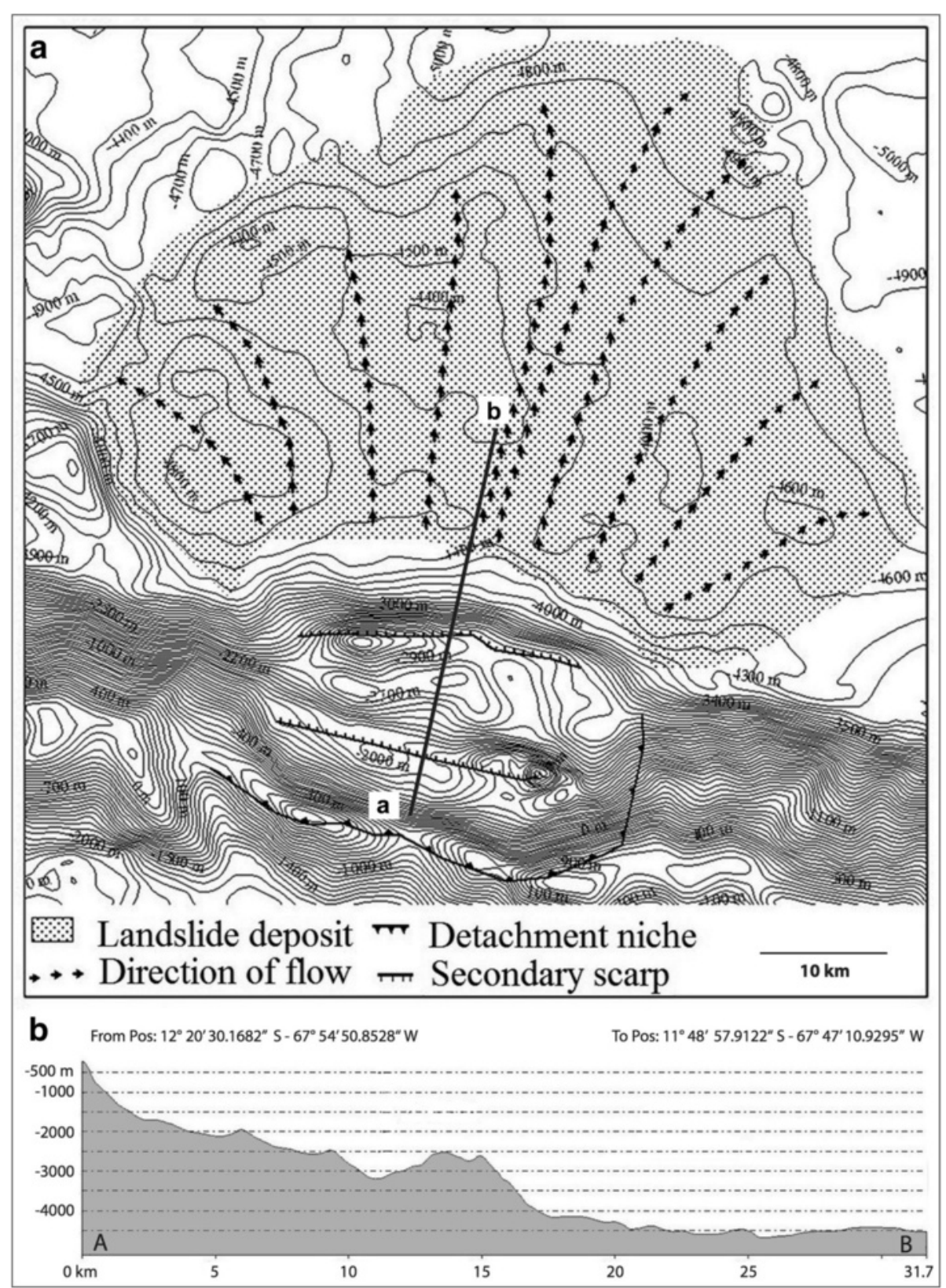

Fig. 7 a Elevation maps of the Coprates Labes landslide. b Elevation through the section $A-B$

\section{Calculation of the landslides emplacement velocities \\ Outline}

Insights into the dynamic behavior of the landslides are derived by geomorphological analysis. Firstly, for Melas Chasma (Figs. 2, 3, and 4) and Ophir Labes (Figs. 5 and 6) landslides, we have examined the cases of front runup at the specific mounds:

- If the landslide front has come to a halt on a topographic rise, the elevation of the perched front and its horizontal length allow us to estimate the maximum velocity at the foot of the rise.

- If the landslide has traveled beyond the rise, dynamical criteria provide only a lower threshold for the velocity.

The velocities are estimated by assuming both scenarios of subaerial and underwater conditions, as detailed below. Moreover, we also use furrow curvature as a second criterion to estimate the velocity. The run-up criterion cannot be used for the Coprates Labes landslide 
(Fig. 7), as there are no topographic accidents along its path.

\section{Subaerial landslide velocity estimates based on run-up Basic equations}

In some of the examples illustrated in "Detailed description of the landslides", the front of the landslide has come across the base of a topographic rise (also called "mound" throughout this work without any reference to its possible origin; see Fig. 8a), rising up a total height difference $H$ from an initial topographic elevation which can be set equal to zero. The velocity for the front as a function of the horizontal coordinate $x$ measured from the foot of the detaching mass may be estimated from elementary dynamics as

$$
U(x)=\sqrt{U_{0}^{2}-2 g[H(x)+\mu x]}
$$

where $x=0$ is the position at the foot of the mound where the landslide has a speed $U_{0}, g=3.7 \mathrm{~m} / \mathrm{s}^{2}$ is the intensity of the Martian gravity field, and $\mu$ is the (dimensionless) effective friction coefficient, assumed constant in this calculation.

The landslide stops when the argument of the square root in (1) becomes zero. Thus, upon measuring the horizontal travel on the mound $R$ and the height difference $H$ between the position of the landslide front at the mound foot and at the maximum height reached, this criterion provides an estimate for the velocity at the foot

$$
U_{0}=\sqrt{2 g[\mu R+H]}
$$

In the case of subaerial landslides, the friction coefficient can be determined using the standard expression $\mu=\Delta H$ / $\Delta R$ where $\Delta H$ and $\Delta R$ are respectively the fall height and the runout for the whole landslide (Scheidegger 1973). Although the center of mass should be used in calculating this ratio, often the so-called Fahrböschung, in which the front and scar points are considered as a substitute to the more complicated center of mass, is introduced as a proxy. Because the front of the landslide has a long longitudinal spreading compared to the center of mass, the Fahrböschung is only an approximation to the friction coefficient (e.g., Dade and Huppert 1998; Lucas and Mangeney 2007; Lucas et al. 2011) which, however, can be considered satisfactory in most cases (e.g., Straub 2001; Lajeunesse et al. 2006; Staron and Lajeunesse 2009; De Blasio 2011b). Considering the uncertainties in the landslide deposit thickness, here we necessarily considered this approximation in the estimation of the apparent friction coefficient, as also done by Quantin et al. (2004a).

If the landslide has traveled past the mound of height $H_{\text {MOUND }}$ (Fig. $8 \mathrm{~b}$ ), then only a minimum value of the velocity $U_{\text {MIN }}$ at the base of the mound can be inferred as

$$
U_{0}>U_{\mathrm{MIN}}=\sqrt{2 g\left[\mu R+H_{\mathrm{MOUND}}\right]}
$$

If, however, the part of the landslide that traveled on the mound was completely rigid, then it is more appropriate to use the position of the center of mass rather than the front in the determination of the velocity. In this case, as a substitute of the values of $R$ and $H$, one should use $R_{C M}$ and $H_{C M}$, which are, respectively, the horizontal and vertical positions of the center of mass on the mound. In the assumption that the mound has a straight profile, the relationship is simply $R_{C M}=R / 2$ and $H_{C M}=H / 2$ (Fig. 8b).

\section{Results}

The velocity calculated based on the front and on the center of mass are summarized in Fig. 9 and in Table 2. For the Melas Chasma landslide (Fig. 2), we find that the velocity at a distance of about $40 \mathrm{~km}$ from the scarp has been greater than $100 \mathrm{~m} / \mathrm{s}$ (i.e., more than $360 \mathrm{~km} / \mathrm{h}$ ). Considering the huge kinetic energy involved, it is hardly surprising that a series of gigantic pressure ridges were shaped some $20 \mathrm{~km}$ in front of the mound A. Another interesting feature is the vanishing of the flow lines on top of the mound A and their re-appearance some kilometers to the lee side. To explain this feature, we first notice that the

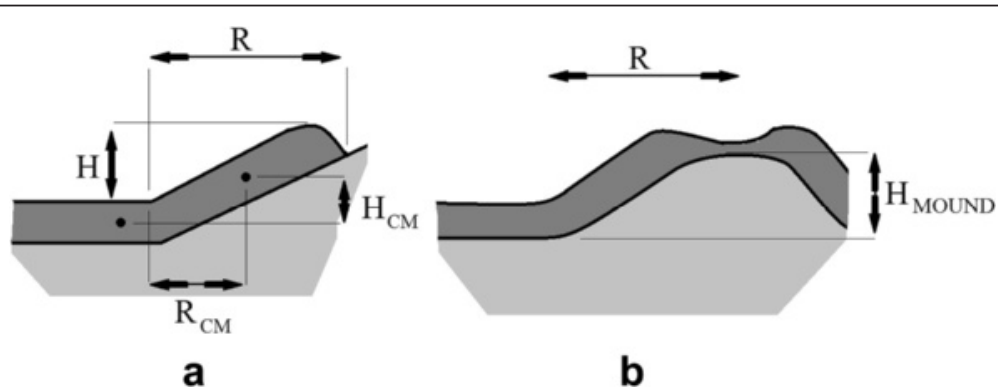

Fig. 8 Scheme of velocity estimates from MOLA elevations. a Based on run-up, when the front stops on the rise. $\mathbf{b}$ Based on run-up, if the front travels past the rise 


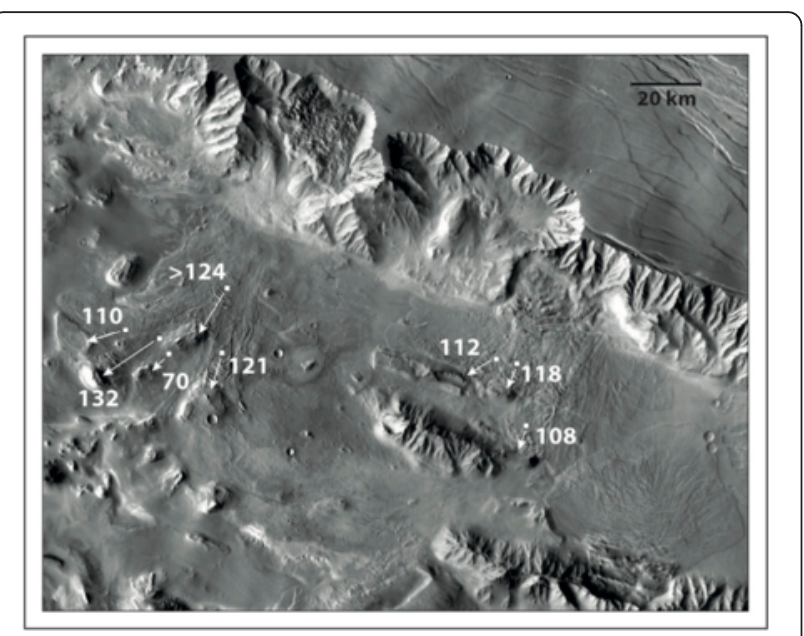

Fig. 9 The maximum velocities calculated with the run-up criteria. The velocity is determined for the points of lower elevation (shown with squares) based on the run-up reached at the top of the mound (the tip of the arrow). The arrow length thus represents the value of $R$ used in Eqs. (2) and (3)

horizontal length $Q$ reached by an object cast at velocity $\mathbf{v}$ with an angle $\theta$ with respect to the horizontal is $Q=\mathbf{v}^{2}$ $\sin (2 \theta) / g$; at the Mars' gravity field, an object launched at $45^{\circ}$ at the estimated speed of the Melas Chasma landslide would leap for a remarkable length of about $2.7 \mathrm{~km}$. Thus, to explain the short-term absence of flow lines past the mound in A, we suggest that the landslide traveled partly detached from the ground. Concerning the other mounds B-E located around the terminal part of the landslide and on which it has come to rest, our estimates show that prior to rising up the mounds, the landslide front still had a velocity of $70-80 \mathrm{~m} / \mathrm{s}$.

The estimated velocities of Ophir Labes (Fig. 5) are even higher, partly because the mounds, where the velocities are computed, are closer to the scarp. The tremendous impact with the nearest mound (position $\mathrm{F}$ in Fig. 5) at a speed of more than $118 \mathrm{~m} / \mathrm{s}$ has truncated the landslide in two parts; the central portion has continued traveling to the next mound at a speed of 110$120 \mathrm{~m} / \mathrm{s}$, finally coming to rest on its top (position $\mathrm{H}$ ). The OL-C mass did not rise much up the western mound in G. The reason may be that the landslide, after having been curved by the impact, flowed nearly parallel to the 300-m-high barrier. As a consequence, the maximum run-up height was diminished by two orders of magnitude compared to head-on impact assuming an angle of about $10^{\circ}$. The skewed impact generated the peculiar pressure ridges nearly parallel to the flow.

To better understand the origin of such longitudinal pressure ridges, we have run some simple tests simulating the landslide with $5 \mathrm{~L}$ of coarse sand flowing down a Plexiglas flume (Fig. 10a, b). After acceleration along the flume inclined by $40^{\circ}$, the granular material falls onto a flat plate. On one side of the plate, there is a vertical wall nearly parallel to the sand. Figure $10 \mathrm{~b}$ shows a top-view image of the result. Note that many ridges are longitudinal to both the flow direction and the wall, in marked similarity with OL-C (Fig. 5). It appears that, despite the violence of impact, the western OL landslide did not travel much on top of the mound (west of the point G). The dynamical explanation for this behavior is discussed in the next

Table 2 Velocities in meters per second of the landslide front for the landslides examined in this study

\begin{tabular}{|c|c|c|c|c|c|}
\hline Point & $\begin{array}{l}\text { Height } \\
\text { reached on } \\
\text { mound }(\mathrm{m})\end{array}$ & $\begin{array}{l}\text { Distance } \\
\text { reached on } \\
\text { mound }(\mathrm{m})\end{array}$ & $\begin{array}{l}\text { Front subaerial velocity (in parenthesis the } \\
\text { one calculated based on the center of } \\
\text { mass), m/s }\end{array}$ & $\begin{array}{l}\text { Front subaerial } \\
\text { velocity, no } \\
\text { friction, } \mathrm{m} / \mathrm{s}\end{array}$ & $\begin{array}{l}\text { Front subaqueous velocity, (in parenthesis } \\
\text { the one calculated based on the center of } \\
\text { mass), } \mathrm{m} / \mathrm{s}\end{array}$ \\
\hline $\begin{array}{l}\mathrm{A} \\
(\mathrm{MC})\end{array}$ & 900 & 15,000 & $>124.6(>88.1)$ & $>81.6$ & $60.4(40.9)$ \\
\hline $\begin{array}{l}\mathrm{B} \\
(\mathrm{MC})\end{array}$ & 310 & 4500 & $70.4(49.8)$ & 47.8 & $35.0(23.8)$ \\
\hline $\begin{array}{l}\mathrm{C} \\
(\mathrm{MC})\end{array}$ & 850 & 19,000 & 132.4 (93.6) & 79.3 & $59.6(40.3)$ \\
\hline $\begin{array}{l}\mathrm{D} \\
(\mathrm{MC})\end{array}$ & 450 & 15,000 & $110.5(78.1)$ & 57.7 & $44.3(30.0)$ \\
\hline $\begin{array}{l}\mathrm{E} \\
(\mathrm{MC})\end{array}$ & 790 & 15,000 & $121.3(85.8)$ & 76.4 & 56.9 (38.6) \\
\hline $\begin{array}{l}\mathrm{F} \\
(\mathrm{OL})\end{array}$ & 1000 & 11,000 & $117.9(83.4)$ & 86.0 & $62.6(42.5)$ \\
\hline $\begin{array}{l}\mathrm{G} \\
(\mathrm{OL})\end{array}$ & 900 & 10,000 & $112.1(79.3)$ & 81.6 & $59.4(40.4)$ \\
\hline $\begin{array}{l}\mathrm{H} \\
(\mathrm{OL})\end{array}$ & 950 & 8000 & $108.0(76.7)$ & 83.8 & $60.6(41.2)$ \\
\hline
\end{tabular}

Values in parenthesis are calculated for the center of mass. Data with zero friction coefficient provide the corresponding estimate if the kinetic energy is entirely converted in gravitational rise at the obstacle. The friction coefficients for the subaerial and the subaqueous cases used in the calculations are 0.08 and 0.005 , respectively 


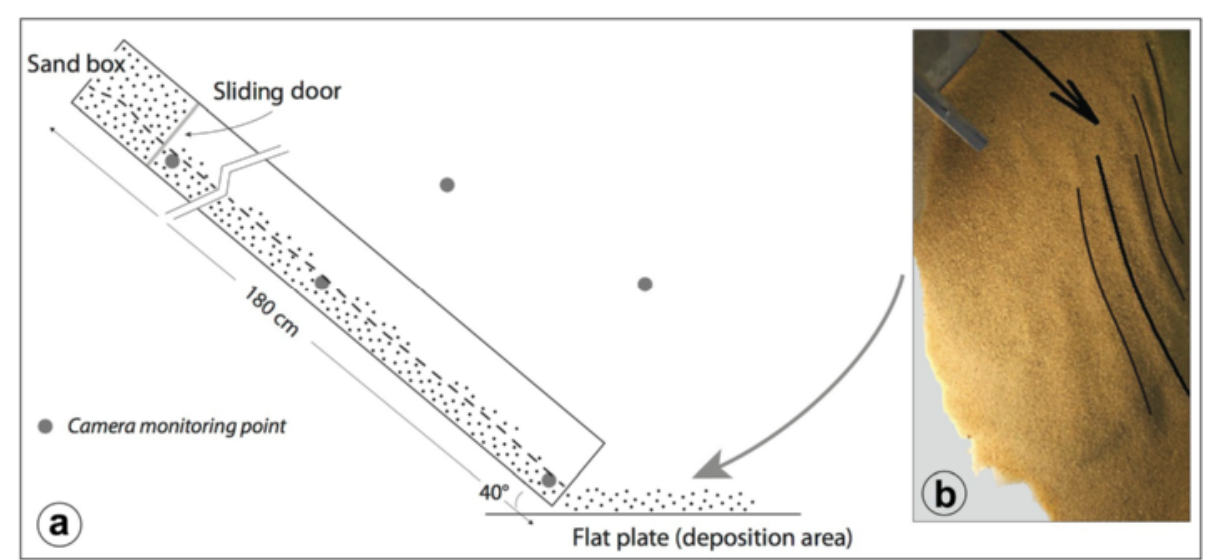

Fig. 10 a Sketch of the cross section of the sand box flume experimental apparatus. b Picture from the top of the sand deposit (light brown), showing pressure ridges (black lines) sub-parallel to flow generated by the impact with a wall nearly parallel to the flow direction

section. Velocities based on the center of mass are $\sqrt{2}$ lower, assuming a constant landslide thickness.

\section{Landslide velocity estimate based on furrows curvature Basic equations}

The longitudinal furrows at the front of VM landslides often appear bent laterally (see, e.g., Fig. 11). A simple kinematic model neglecting friction explains such bending effect as a consequence of diminished speed of the landslide traveling along local topographic inclination (De Blasio 2011b). In the following analysis, where also basal friction is introduced, we apply this effect for actual velocity determination.

Assuming that the landslide front approaches a flat area inclined with an angle $\gamma$ with respect to the horizontal, the equation of motion is (Fig. 11a)

$$
\begin{aligned}
\frac{d U_{X}}{d t} & =g[\sin \gamma-\mu \cos \gamma] \\
\frac{d U_{Y}}{d t} & =-\mu g \cos \gamma
\end{aligned}
$$

where $X$ is the coordinate directed along the maximum slope, $Y$ is the coordinate parallel to slope (Fig. 11a), and $U_{X}, U_{Y}$ are the velocities along these directions. The slope of one trajectory can be found as a parametric equation in time

$$
\frac{d y}{d x}=\frac{U_{y}}{U_{x}}=\frac{U_{0 y}-\mu g \cos \gamma t}{U_{0 x}+g[\sin \gamma-\mu \cos \gamma] t}
$$

If the landslide enters the flat area parallel to slope $\left(U_{0 x}\right.$ $=0 ; U_{0 y} \neq 0$ ), with time it will gain a velocity component also along $x$; after a time $\tau=U_{0 y} / \mu g \cos \gamma$ (at which point Eq. (5) breaks down), the velocity becomes directed along the slope $\left(U_{0 x} \neq 0 ; U_{0 y}=0\right)$, at $90^{\circ}$ from the initial direction. In addition to the underlying topography, the direction of the flow lines will also be affected by the lateral expansion of the landslide. However, as shown by ice-related landslides as for example of Sherman (De Blasio 2014), lateral

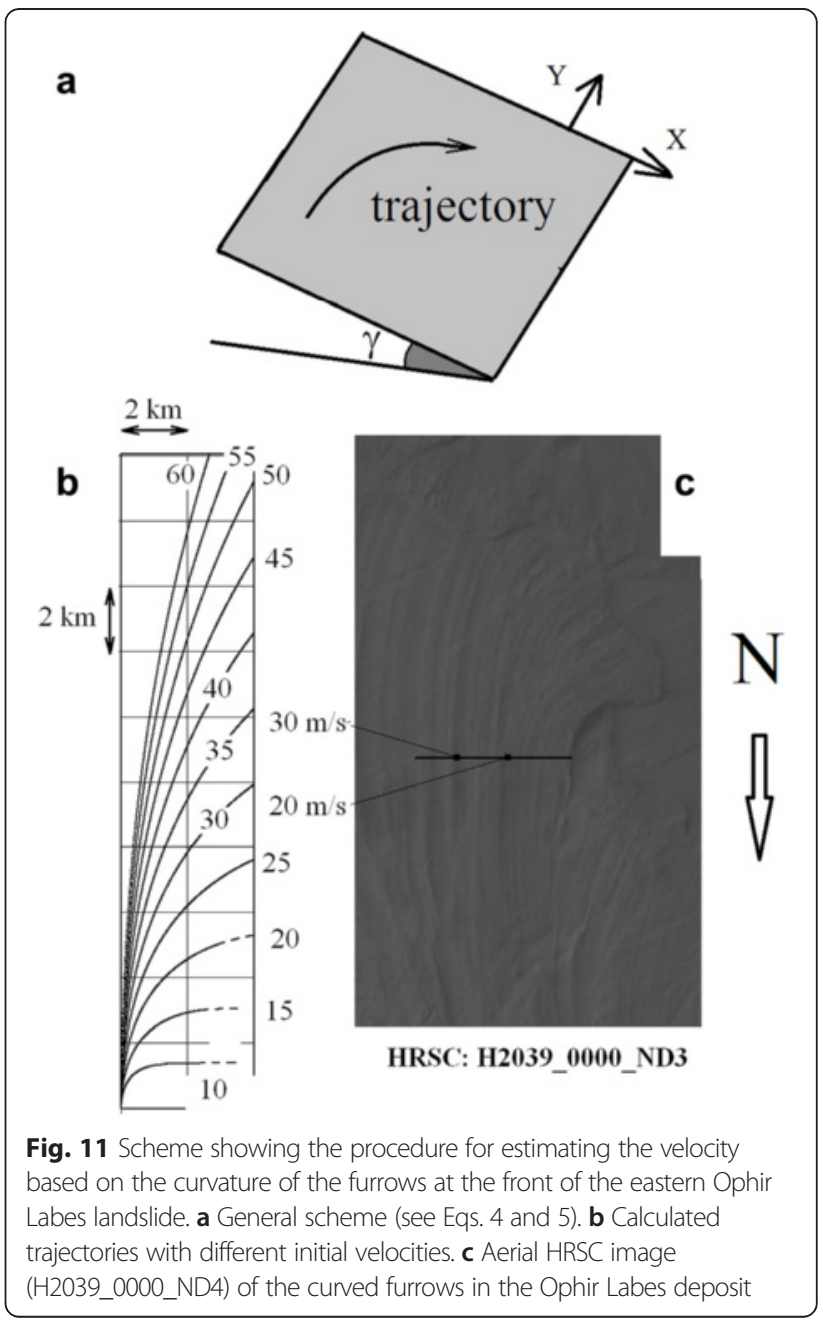


expansion would typically result in diverging flow lines on a flat area, while at even low topographic inclinations the role of the inclined topography is likely to be prevalent.

\section{Results}

The front of the eastern Ophir Labes landslide shows a particularly strong bending effect that we utilize here for velocity determination. Using Eq. (5), it is possible to draw a set of trajectories with different values of the initial velocity $U_{0 x}, U_{0 y}$. Then, by comparing the theoretical curves with the furrows observed on the deposit, we can estimate the most likely initial velocity.

Figure $11 \mathrm{~b}$ shows the trajectories calculated for $\mu=0.01$ and inclination of $1.2^{\circ}$, compatible with the average eastward slope of the valley floor in that part of Melas Chasma. Note that the friction coefficient must have become lower than $\tan \left(1.2^{\circ}\right)=0.021$ during the flow, else the front would not have curved perpendicularly. Because the average friction calculated through the whole landslide path is much higher (of the order $H / R$, corresponding to the Fahrböschung in Table 1), this is an indication that the friction is velocity-dependent.

By a visual comparison between calculated trajectories (Fig. 11b) and the furrows crossing the black line section in the HRSC image (Fig. 11c), a velocity of the order $20-30 \mathrm{~m} / \mathrm{s}$ was estimated. The curvature of the furrows confirms the expected inference that the velocity was lower toward the edge of the landslide. This conclusion rests on the hypothesis of constant slope angle and absence of hidden topography underneath the landslides.

\section{Calculations for subaqueous landslides}

The mechanical effects of water on a fast landslide can be summarized as follows (e.g., De Blasio 2011b). On the one hand, water hinders the flow due to the effects of buoyancy and drag. On the other hand, significant water effects such as hydroplaning (Mohrig et al. 1998) and water incorporation at the basal high-shear layer may substantially decrease the resistance at the bottom. In fact, subaqueous landslides on Earth have longer runout compared to subaerial landslides, even though the average velocity is probably decreased (e.g., De Blasio et al. 2006).

To estimate the velocities in the hypothesis of subaqueous landslides, we back-estimate the effective friction coefficient which gives the observed final runout. We consider the Melas Chasma landslide, which is more likely to be the product of one single failure. In this way, a friction coefficient of 0.005 is found to reproduce the observed runout of $72 \mathrm{~km}$. Appendix 2 presents the details of the velocity calculations for the case of subaqueous mass flow, and Fig. 12 shows the velocity as a function of the distance for the Melas Chasma landslide in comparison with a calculation without water. Owing

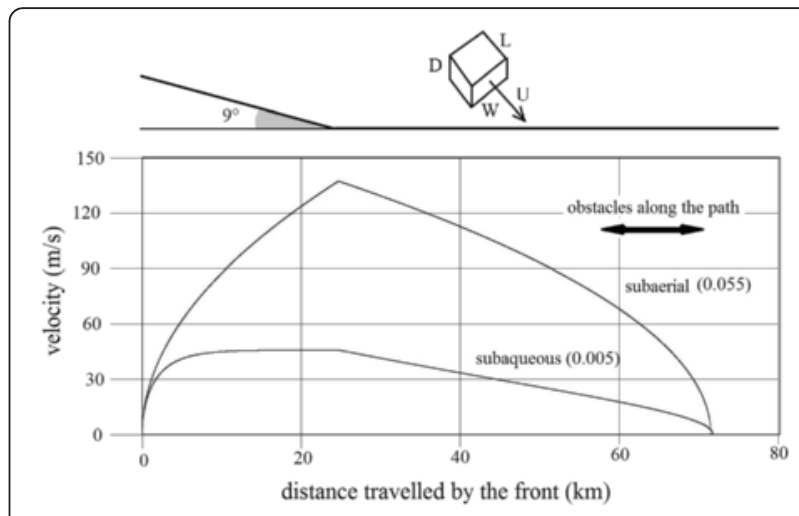

Fig. 12 Simulation of the velocity of the front of a subaerial and subaqueous slab traveling along a slope path compatible to the Melas Chasma landslide. Maximum velocities are attained at the break of slope, followed by a decrease of velocity

to the drag force, velocities are much reduced in water despite the lower friction coefficient (Table 2). The velocity on the inclined part of the trajectory attains an asymptotic value of about $46 \mathrm{~m} / \mathrm{s}$ before coming to the flat area (Fig. 12). In comparison, subaerial velocities are much greater, with maximum velocity at the base of the ramp of $136 \mathrm{~m} / \mathrm{s}$.

\section{Discussions}

One of the goals of landslide examination is to contribute inferring the ancient Martian environment based on their morphology and runout. There has been much conjecture as to the past environment and climate of Valles Marineris. Following the previous morphological analysis and dynamical calculations, we now discuss in turn the subaqueous and subaerial scenarios for landslides in Valles Marineris.

Based on morphologic, sedimentologic, petrographic, and hydrologic evidence, it has been hypothesized that large parts of Valles Marineris was filled by temporary ponding or a lake (Lucchitta 2010) whose estimated depth in Melas-Coprates Chasmata was about $1.5 \mathrm{~km}$. The lake subsequently drained toward north (Ori et al. 2000; Harrison and Chapman 2008, 2010; Lucchitta 2009; Metz et al. 2009; Flahaut et al. 2010; Lucchitta 2010; Sowe et al. 2011; Warner et al. 2013). Thus, depending on the timing of the lake disappearance in relation to the landslide events, it is possible that at least some of the most ancient landslides were subaqueous. As an alternative to the subaerial, "dry" model for Valles Marineris landslides (e.g., McEwen 1989), and to waterrich yet not completely submerged environment (Lucchitta 1987; Harrison and Grimm 2003), some authors (Shaller 1991) suggested a fully submerged scenario for the landslides.

In the last decades, the knowledge on subaqueous landslides has increased considerably; morphologies have 
been visualized in great detail with sidescan sonar and multibeam echosounder, whereas corings have provided rich samples of oceanic sediments, allowing to distinguish genuine landside deposits from other sediments such as turbidites (Locat and Lee 2002). The ratio H/L for subaqueous landslide deposits may reach extremely low values, demonstrating that subaqueous landslides are more mobile than their subaerial counterparts (e.g., Locat and Lee 2002; De Blasio et al. 2006; Shanmugam 2015). Because water exerts a strong drag hindrance on a fast-moving landslide (Eq. (6) in Appendix 2 shows that the drag increases with the square of the velocity), it follows that submarine mass flows travel exploiting a phenomenon like hydroplaning (Mohrig et al. 1998) capable of outcompeting the drag force (e.g., De Blasio 2011b; Shanmugam 2015).

The simulation of Fig. 12 shows that the maximum subaqueous velocities are reduced approximately to the $34 \%$ with respect to the peak subaerial velocity. The minimum velocity for the observed run-up at the mounds is then calculated similar to the subaerial case, but using Eq. (10) which accounts for the drag and buoyancy effects. Table 2 shows a noticeable reduction of the calculated velocity at the base of the mounds. For example, the velocity of the front of MC landslide at position $\mathrm{C}$, estimated at $132.4 \mathrm{~m} / \mathrm{s}$ for subaerial failure, is reduced to $59.6 \mathrm{~m} / \mathrm{s}$ in the subaqueous case. Similar reductions are observed for all the positions $\mathrm{A}-\mathrm{H}$ (Table 2).

The results of the calculation show that in the region where the front of the landslide has met the topographic obstacles along the path, indicated in Fig. 12 as a double arrow, the subaqueous velocity would have been lower than $20 \mathrm{~m} / \mathrm{s}$, much less than the velocities required to reach the top of the mound points $\mathrm{A}-\mathrm{D}$. In other words, the observed run-ups would have required higher velocities than those calculated and shown in Fig. 12. Subaerial velocities calculated for the region of the obstacles are more compatible with the ones reported in Table 2. Thus, Fig. 12 and Table 2 taken in conjunction are another indication that the examined landslides were likely subaerial, rather than subaqueous.

The furrows on top or most of the landslides in VM are much similar to those found on terrestrial rock avalanches falling onto glaciers (Lucchitta 1987; Shreve 1966; McSaveney 1978). As the rock avalanche follows the local gradient and opens up in a fan, single parts may tear apart in linear zones which materialize as the longitudinal furrows when the landslide fully develops. Furrows thus require a soft and slippery basal layer for their formation and small friction (Lucchitta 1987; De Blasio 2011a) that makes the role of inertia dominant (Dufresne and Davies 2009). Our suggested situation is thus that landslides were lubricated by ice of a partly glaciated VM (Lucchitta 1987). In this respect, two possible scenarios can be suggested. In the first scenario, ice impregnates the pores of the subsurface regolith. Upon collapse of the rock mass, intense frictional heat concentrated at the sliding base leads internal ice to melting. The resulting water may lubricate the landslide not only reducing the effective friction, but also because wetted fines mixed with water work as a layer of nonNewtonian fluid (De Blasio 2009).

In a second situation, suggested by terrestrial landslides collapsing onto glaciers, ice existed in the form of a large glacier-like body. The diffusion rate of ice sublimating in the Martian atmosphere decreases considerably if ice is protected by rock rather than being directly exposed to the atmosphere (Mellon and Jakosky 1993). If sublimation is small, ice underneath a protective rock layer might persist for a geologically long time (Clifford and Hillel 1983; Mellon et al. 1997). However, in this case, a series of questions arise as to the dynamics of a landslide on debris-covered ice. How then does the ice lubricate the slides? Is the protective rocky layer thin enough to be negligible with respect to the lubrication effect? A possible answer could be that this layer would be easily removed by the immense shear stress exerted by a thick landslide, which after scraping the layer off would essentially travel on bare ice.

It has been shown that the curved front of the Ophir Labes landslide and of many landslides in VM requires the friction coefficient at the front be less than the tangent of the slope angle parallel to the valley axis. This is possible only if the friction has diminished quite dramatically during the flow, which is consistent with ice lubrication (De Blasio 2014). According to recent work by Gourronc et al. (2014), some features in Valles Marineris are compatible with a full glacial regime. However, exposed ice in the form of a glacier might be problematic in terms of thermodynamical stability of ice on equatorial Mars; moreover, the deposits would have been displaced by subsequent ice flow (De Blasio 2011a). Multiple landslides fallen on previous deposits of VM exhibit longitudinal furrows, which is compatible with ice within the regolith, rather than exposed (or at least a debris-covered glacier); similar furrows are observed on the multi-layered ejecta of impact crater at middle and low latitudes (Weiss and Head 2013). This might confirm the likely role of ice in the inertial movement of the rock.

Note also that velocities of this order would cause strong shear and disruption of the landslide body in a subaqueous environment, which is in contrast with the regular appearance of the landslides in VM. Considering that the presence of a thick water layer would have protected the soil from excavation of middle-sized craters, the water scenario is also less compatible with the 
numerous large craters on the surface of many of the ancient landslides. Moreover, the very different ages of landslides in VM (Quantin et al. 2004b) would require the constant presence of water throughout much of its history (Table 1).

\section{Conclusions}

We have described in detail three contiguous landslides in Valles Marineris on Mars, with emphasis on the morphological details that can shed light on their dynamics and velocity. The regular geometry of a landslide that traveled unconfined on a flat area (Coprates Labes) has to be contrasted with the irregular shape and complexity of landslides traveling on an irregular ground (Melas Chasma and Ophir Labes landslides). Thus, the prelandslide topography is of fundamental importance in the dynamics of these landslides. In spite of the lower gravity field on Mars, we find indications that the landslides traveled with velocities larger than most landslides on Earth, with maximum velocities greater than $100 \mathrm{~m} /$ s. This is a consequence of the extreme height of the VM walls compared to the detachment elevation of most terrestrial landslides (i.e., higher energy relief) which resulted in high potential energy involved despite the lower gravity field on Mars. Even though deep water for these landslides would provide a means for lubrication and long runout, velocity estimations and the morphology suggest a subaerial, rather than subaqueous failures in Valles Marineris. Our conclusion, however, does not necessarily rule out the presence of lakes in Valles Marineris, for at least two reasons. Firstly, the lake might have emptied prior to the landslide collapses, as the $3 \mathrm{Ga}$ or older dating for the outflow event proposed by Warner et al. (2013) would suggest; secondly, the lake lifetime (or lifetimes in the case of repeated ponding) could have been much shorter than landslide recurrence time, implying a higher probability of landslide collapse during the longer periods of water absence.

However, some lubrication mechanism should be invoked to explain both the high mobility and the important role played by inertia against basal friction. The morphologies, much similar to landslides traveling on glaciers, suggest ice as a possible lubrication medium. In one possible scenario, ice was present in the pores of the rock surrounding the Valles Marineris flanks. Alternatively, ice might have been located at the base of the valley, protected by a layer of regolith. Any of these two scenarios, which would explain the glacial style and mobility of the VM landslides, also conform to the possible occurrence of Amazonian glaciations at mid-latitudes (e.g., Laskar et al. 2004; Madeleine et al. 2009) and the potential presence of ice at equatorial latitudes within some hundreds of meters depth.

\section{Highlights}

- Velocities of two landslides in Valles Marineris (Mars) are determined based on morphological analysis

- High velocities (>80-90 m/s) and long runout confirm the presence of a lubricating medium

- Climatological consequences may be relevant

\section{Appendix 1}

\section{Data and methods}

This study is based on several imaging and data systems aboard post-Viking missions to Mars. Optical images are based on High-Resolution Stereo Camera aboard Mars Express (HRSC; Neukum et al. 2004) at about $10 \mathrm{~m}$ resolution and Context CTX camera on board Mars Reconaissance Orbiter (Malin et al. 2007). Because we are in every case interested in details wider than several tens of meters (but more often longer than $1 \mathrm{~km}$ ), the resolutions are more than satisfactory for our purposes.

The MOLA instrument aboard the Mars Global Surveyor (MGS) has measured the elevation of the Martian topography based on the return times of laser pulses. We used MOLA data based on the JMARS platform provided by NASA. A correct use of MOLA is critical for the present work, where the elevations are directly used for velocity estimations. We first verified that the MOLA measurements in the Melas-Coprates areas examined here were sufficiently dense. For the estimates of the maximum elevation reached by the landslide front, we have chosen points close to measured elevations. To determine the landslide thickness, we drew sections through lines of good MOLA data points measured intercepting transversally the main body of the deposit.

Thermal Emission Imaging Spectrometer (THEMIS) is a spectrometer sensitive to visible $(0.43-0.86 \mu \mathrm{m})$ and infrared radiation $(6-15 \mu \mathrm{m})$ with a resolution of $100 \mathrm{~m}$ per pixel (Christensen et al. 2004a). THEMIS can potentially show temperature differences of the different regions of the Martian soil, a property exploited in the examination of the thermal inertia, $I=\sqrt{\chi \rho C}$ where $\chi, \rho$, and $C$ are respectively the thermal conductivity of the soil $(\mathrm{W} / \mathrm{m} \mathrm{K})$, its density $\left(\mathrm{kg} / \mathrm{m}^{3}\right)$, and the specific heat $(\mathrm{J} / \mathrm{kg} \mathrm{K})$. The thermal inertia (units $\mathrm{J} / \mathrm{m}^{2} \mathrm{~K} \mathrm{~s}^{1 / 2}$ ) gives the capability of the soil to retain its temperature with time (e.g., Melosh 2011). Because the conductivity and density are low for rock in a fragmented state, the comparison between the daytime and nighttime thermal emissions allows inferring the thermal inertia of the medium, from which it is possible to distinguish the regions with outcrops of bare rock from those where sand or powder dominate. 
The experimental test that reproduced the pressure ridges nearly parallel to flow is shown in Fig. 10. The 1.8-m-long flume visible in the figure is inclined to an angle of $40^{\circ}$. A box on the upper end of the chute is filled with $5 \mathrm{~L}$ of 2 -mm-diameter sand. When the frontal gate is lifted up, the sand flows along the chute and then collapses onto a horizontal plate. The lateral wall along which the pressure ridges develop is placed nearly parallel to the flow direction (angle of about $10^{\circ}$ ), as shown in the figure.

\section{Appendix 2}

\section{Equation of motion for a subaqueous landslide modeled} as a slab

For simplicity, we consider a landslide as a parallelepiped block of width $W$, length $L$, and thickness $D$ (De Blasio 2011b). The equation of motion of the block immersed in water is of the form

$$
\frac{d U}{d t}=\frac{g}{\eta} \frac{\Delta \rho}{\rho}[\sin \beta-\mu \cos \beta]-\frac{U^{2}}{k \eta}
$$

where $\frac{\Delta \rho}{\rho} \equiv \frac{\rho-\rho_{F}}{\rho}=1-\frac{\rho_{F}}{\rho}$ is the Archimedean term which decreases the effective gravity to $g^{\prime}=g \frac{\Delta \rho}{\rho}, g=3.71 \mathrm{~m} / \mathrm{s}^{-2}$ is Mars gravity acceleration, $\rho, \rho_{F}$ are the densities of the landslides and of water, respectively, and $\eta=\left(1+\alpha \frac{\rho_{F}}{\rho}\right)$ is the (dimensionless) added mass term, with $\alpha$ being of the order of the ratio between the landslide linear size perpendicular to the one parallel to the direction of movement. We will consider $\eta=1.4$ in the calculations. Note that Eq. (6) is formally equivalent to the one from the Voellmy model (Voellmy 1955). The drag term $k$ (which has the dimension of $\mathrm{m}$ ) can be written in terms of the dimension of the block as

$$
\frac{1}{k}=\frac{1}{2} \frac{\rho_{F}}{\rho}\left[\frac{C_{D}}{L}+\frac{C_{S}}{D}+2 \frac{C_{S}}{W}\right]
$$

where $C_{D} \approx 0.8, C_{S} \approx 0.003$ are the dimensionless front drag and skin friction coefficients, respectively, and $L, D$, and $W$ are, respectively, the block length, height, and width (Fig. 12).

Because

$$
\frac{d U}{d \lambda}=\frac{1}{U} \frac{d U}{d t}=\frac{a}{U \eta}-\frac{U}{k \eta}
$$

where $a=g \frac{\Delta \rho}{\rho}[\sin \beta-\mu \cos \beta] \equiv-g \frac{\Delta \rho}{\rho} \gamma$ where $\gamma=\mid \sin \beta$ $+\mu \cos \beta \mid(\sin \beta$ is negative in this calculation, since the landslide is traveling uphill) and $\lambda$ is the length parallel to the the terrain, multiplying both members of Eq. (8) with $U$, we can re-write it as

$$
\frac{d U^{2}}{d \lambda}=\frac{2 a}{\eta}-\frac{2 U^{2}}{k \eta}
$$

which can be readily integrated to give

$$
U(\lambda)=\sqrt{\left(k a+U_{0}^{2}\right) \exp (-2 \lambda / k \eta)-k a} .
$$

Setting $U(\lambda)=0$ where $\lambda$ is the total length traveled on the mound, we find the velocity at the foot of the mound as

$$
U_{0}=\sqrt{k a[\exp (2 \lambda / k \eta)-1]}
$$

which in the limit of small argument for the exponential $(k \eta>>2 \Lambda)$ becomes

$$
U_{0}=\sqrt{2 \lambda a / \eta} \sqrt{1+\frac{\lambda}{k \eta}+\frac{2}{3} \frac{\lambda^{2}}{k^{2} \eta^{2}}}
$$

Note that the first square root reduces formally to the result valid for subaerial landslides, i.e., $U_{0}$ $=\sqrt{2 g\left[\mu R+H_{F}-H_{0}\right]}$; thus the effect of water occurs in the second square root of Eq. (11). However, the subaqueous friction is not simply equal to the ratio $\mu=\Delta H / \Delta R$ like for the subaerial case (Scheidegger 1973) and needs to be back-calculated. Using the same friction coefficient as for the subaerial case, the effect of the drag force would stop the landslide much earlier than observed. Subaqueous landslides are known to travel with much lower effective friction than subaerial ones (e.g., De Blasio et al. 2006).

To estimate the friction coefficient in the case of subaqueous landslide, in a separate calculation we consider a slab traveling down an inclined ramp as a simple model for the Melas Chasma landslide. The ramp is inclined with an angle of $9^{\circ}$ compatible with the observed average slope topography (note that the angles $\sim 15^{\circ}-17^{\circ}$ measured in the alcove would rather correspond to the scar inclination rather than to the surface of flow). Along the ramp, the landslide has initial width, length, and height of $W=20 \mathrm{~km}$, $L=1 \mathrm{~km}$, and $D=1.2 \mathrm{~km}$. Once reached the slope break $25 \mathrm{~km}$ from the initial position, it changes its lengths to $W=20 \mathrm{~km}, L=5 \mathrm{~km}, D=0.15 \mathrm{~km}$. Thus, in this calculation, the mass is not conserved at the slope break as a consequence of the deposition before and at the slope break. The equation of motion is then solved using Eqs. (6-7); the velocity as a function of the position is reported in Fig. 12. The friction coefficient giving the observed runout of about $72 \mathrm{~km}$ for the subaqueous case is so backestimated to be 0.005, which is in accordance with values for subaqueous landslides, for example, the Grand Banks landslide (De Blasio 2011b). 


\section{Competing interests}

The authors declare that they have no competing interests.

\section{Authors' contributions}

PM is responsible for the geomorphological analyses and interpretation and for the paper arrangement. FVDB is responsible for the modeling, geomorphological interpretations, calculations, and paper arrangement. FB revised the overall paper, assisted in geomorphological interpretation, and provided the funding. CDB carried out the geomorphological analysis. All authors read and approved the final manuscript.

\section{Acknowledgements}

Two anonymous reviewers considerably improved the quality of the paper. Marco Albano provided assistance in shaping up some of the figures.

Received: 9 July 2015 Accepted: 3 December 2015

Published online: 06 January 2016

\section{References}

Baker VR (2001) Water and the martian landscape. Nature 412:228-236

Bigot-Cormier F, Montgomery DR (2007) Valles Marineris landslides: evidence for a strength limit to Martian relief? Earth and Planetary Science Letters 260: 179-186

Brunetti MT, Guzzetti F, Cardinali M, Fiorucci F, Santangelo M, Mancinelli P, Komatsu G, Borselli L (2014) Analysis of a new geomorphological inventory of landslides in Valles Marineris, Mars. Earth and Planetary Science Letters 405:156-168

Bulmer MHK (2012) Landslides on other planets. In: Clague JJ, Stead D (eds) Landslides: types, mechanisms and modelling. Cambridge Univ. Press, Cambridge, pp 393-408

Carr M (2006) The surface of Mars. Cambridge Univ. Press, Cambridge

Christensen PR, Gorelick NS, Mehall GL, Murray KC (2004a) THEMIS Public Data Releases. Planetary Data System node, Arizona State University. http://themis-data.asu.edu

Christensen, P.R., B.M. Jakosky, H.H. Kieffer, M.C. Malin, H.Y. McSween, Jr., K. Nealson, G.L. Mehall, S.H. Silverman, S. Ferry, M. Caplinger, and M. Ravine (2004b). The Thermal Emission Imaging System (THEMIS) for the Mars 2001 Odyssey Mission. Space Sci Rev 110, 85-130

Clifford SM, Hillel D (1983) The stability of ground ice in the equatorial region of Mars. Journal of Geophysical Research 88:2456-2474

Crosta GB, Utili S, De Blasio FV, Castellanza R (2014) Reassessing rock mass properties and slope instability triggering conditions in Valles Marineris, Mars. Earth and Planetary Science Letters 388:329-342.

Dade WB, Huppert H (1988) Long runout rock-falls. Geology 26:803-806

De Blasio FV (2009) Rheology of a wet, fragmenting granular flow and the riddle of the anomalous friction of large rock avalanches. Granular Matter May 11:179-184

De Blasio FV (2011a). Landslides in Valles Marineris (Mars): a possible role of basal lubrication by sub-surface ice. Planetary Space Sci 59:1384-1392

De Blasio FV (2011b) Introduction to the Physics of Landslides. Springer, Verlag, Berlin

De Blasio FV (2014) Friction and dynamics of rock avalanches travelling on glaciers. Geomorphology 213:88-98

De Blasio FV, Elverhøi A, Engvik L, Issler D, Gauer P, Harbitz C (2006) Understanding the high mobility of subaqueous debris flows. Norwegian Journal of Geology, special issue on "Submarine mass movements and their consequences" 86:275-284

Dufresne A, Davies TR (2009) Longitudinal ridges in mass movement deposits. Geomorphology 105:171-181

Fairén AG (2010) A cold and wet Mars. Icarus 208:165-175

Flahaut J, Quantin C, Allemand P, Thomas P (2010) Morphology and geology of the ILD in Capri/Eos Chasma (Mars) from visible and infrared data. Icarus 207 $175-185$

Fueten F, Flahaut J, Le Deit L, Stesky R, Hauber E, Gwinner K (2011) Interior layered deposits within a perched basin, southern Coprates Chasma, Mars: Evidence for their formation, alteration, and erosion. Journal of Geophysical Research: Planets (1991-2012) 116:E2

Fueten F, Flahaut J, Stesky R, Hauber E, Rossi AP (2014) Stratigraphy and mineralogy of Candor Mensa, West Candor Chasma, Mars: Insights into the geologic history of Valles Marineris. Journal of Geophysical Research: Planets 119(2):331-354
Gourronc M, Bourgeois O, Mège D, Pochat S, Bultel B, Massé M, Le Deit L, Le Mouélic S, Mercier D (2014) One million cubic kilometres of fossil ice in Valles Marineris: Relict of a 3.5 Gy old glacial landsystem along the Martian equator. Geomorphology 204:235-255

Harrison KR, Chapman MG (2008) Evidence for ponding and catastrophic flood in central Valles Marineris. Icarus 198:351-364

Harrison KP, Chapman MG (2010) Episodic ponding and outburst flooding associated with chaotic terrains in Valles Marineris. In: Cabrol NA, Grin EA (eds) Lakes on Mars. Elsevier, Amsterdam

Harrison KP, Grimm RE (2003) Rheological constrains on martial landslides. Icarus 163:347-362

Hauber E, Grott M, Kromberg P (2010) Martian rift: structural geology and geophysics. Earth and Planetary Science Letters 294(3-4):393-410

Head JW, Marchant DR (2003) Cold-based mountain glaciers on Mars: western Arsia Mons. Geology 31(7):641-644

Kargel JS (2004) Mars: a warmer, wetter planet. Springer Praxis, London

Kelfoun K, Druitt TH (2005) Numerical modeling of the emplacement of Socompa rock avalanche, Chile. Journal of Geophysical Research 110:B12202

Kerr RA (2006) Mars orbiters swan song: the red planet is a changin'. Science 314(5805):1528-1529. doi:10.1126/science.314.5805.1528

Kim JR, Lin SY, Choi YS, Kim YH (2013) Toward generalized planetary stereo analysis scheme-prototype implementation with multi-resolution Martian stereo imagery. Earth Planets Space 65(7):799-809

Lajeunesse E, Quantin C, Allemand P, Delacourt C (2006) New insight on the runout of large landslides in the Valles-Marineris Canyons, Mars. Geophysical Research Letters 33:L04403

Laskar G, Gastineau M, Joutel F, Levrard P, Correia A (2004) Long term evolution and chaotic diffusion on the insulation quantities of Mars. Icarus 170:343-264

Locat J, Lee HJ (2002) Submarine landslides: advances and challenges. Can Geotech J 39:193-212

Lucas A, Mangeney A (2007) Mobility and topographic effects for large Valles Marineris landslides on Mars. Geophysical Research Letters 34:L10201

Lucas A, Mangeney A, Mège D, Bouchut F (2011) Influence of the scar geometry on landslide dynamics and deposits: application to Martian landslides. Journal of Geophysical Research 116:E1001

Lucchitta BK (1979) Landslides in Vallis Marineris, Mars. J Geoph Res 84:8097-8113

Lucchitta BK (1987) Valles Marineris, Mars: wet debris flows and ground ice. Icarus 72:411-429

Lucchitta BK (2009) Lakes in Valles Marineris, Mars (II): valleys, channels, shallow lakes, and age, $40^{\text {th }}$ Lunar and Planetary Conference

Lucchitta BK (2010) Lakes in Valles Marineris. In: Cabrol NA, Grin EA (eds) Lakes on Mars (chapter 5). Elsevier, Amsterdam

Madeleine JB, Forget F, Head JW, Levrard B, Montmessin F, Millour E (2009) Amazonian northern mid-latitude glaciation on Mars: a proposed climate scenario. Icarus 203:390-405

Malin MC, Bell JF III, Cantor BA, Caplinger MA, Calvin WM, Clancy RT, Edgett KS, Edwards L, Haberle RM, James PB, Lee SW, Ravine MA, Thomas PC, Wolff MJ (2007) Context camera investigation on board the Mars Reconnaissance Orbiter. Journal of Geophysical Research 112:E06S04. doi:10.1029/ 2006JE002808

McEwen AS (1989) Mobility of large rock avalanches: evidence from Valles Marineris, Mars. Geology 17:1111-1114

McSaveney M (1978) Sherman glacier rock avalanche, Alaska, U.S.A. In: Voight B (ed) Rockslides and avalanches. Elsevier, Amsterdam

Mellon MT, Jakosky BM (1993) Geographic variations in the thermal and diffusive stability of ground ice on Mars. J Geoph Res 98(2):3345-3364

Mellon MT, Jakosky BM, Postawko SE (1997) The persistence of equatorial ground ice on Mars. J Geoph Res 102(E8):19357-19369

Melosh HJ (2011) Planetary surface processes. Cambridge Univ. Press, Cambridge, p 500

Metz JM, Grotzinger JP, Mohrig D, Milliken R, Prather B, Pirmez C, McEwen AS, Weitz CM (2009) Sublacustrine depositional fans in southwest Melas Chasma. Journal of Geophysical Research 114:E10002

Mohrig DK, Whipple CE, Parker G (1998) Hydroplaning of subaqueous debris flows. Geol Soc Am Bull 110:387-394

Mouginot J, Pommerol A, Beck P, Kofman W, Clifford SM (2012) Dielectric map of the Martian northern hemisphere and the nature of plain filling materials. Geophys Res Lett 39:L02202

Murray JB, Muller JP, Neukum G, Werner SC, Van Gasselt S, Hauber E, Markiewicz WJ, Head JW 3rd, Foing BH, Page D, Mitchell KL, Portyankina G, HRSC Co-Investigator Team (2005) Evidence from the Mars express 
high resolution stereo camera for a frozen sea close to Mars' equator. Nature 434:352-356

Neukum G, Ivanov BA, Hartmann WK (2001) Cratering records in the inner Solar System in relation to the lunar reference system. Space Sci Rev 96:55-86

Neukum G, Jaumann R, and the HRSC Co-Investigator and Experiment Team, HRSC (2004) The High Resolution Stereo Camera of Mars Express, in Mars Express: The scientific payload. In A. Wilson, ESA, Noordwijk, The Netherlands, pp 17-35

Ori GB, Marinangeli L, Komatsu G (2000) Martian paleolacustrine environments and their geological constrains on drilling operations for exobiological research. Planetary and Space Science 48:1027-1034

Parker TJ, Grant JA, Franklin BJ (2010) The northern plain: a Martian oceanic basin? In: Cabrol NA, Grin EA (eds) Lakes on Mars. Elsevier, Amsterdam

Quantin C, Allemand P, Delacourt C (2004a) Morphology and geometry of Valles Marineris landslides. Planetary Space Sci 52(11):1011-1022

Quantin C, Allemand P, Mangold N, Delacourt C (2004b) Ages of Valles Marineris (Mars) landslides and implications for canyon history. Icarus 172:555-572

Reiche P (1937) Toreva block-a distinctive landslide type. Journal of Geology 45 : 538-540

Scheidegger AE (1973) On the prediction of the release and velocity of catastrophic rockfalls. Rock Mechanics 5:231-236

Schultz RA (1998) Multiple-process origin of Valles Marineris basins and troughs, Mars. Planetary and Space Science 46:825-829

Schulz RA (2002) Stability of rock slopes in Valles Marineris, Mars. Geophys. Res. Lett. 29. doi:10.1029/2002GL015728

Shaller PJ (1991) Analysis and implications of large Martian and terrestrial landslides, Ph.D. thesis. Calif. Inst. of Technol, Pasadena, p 586

Shanmugam G (2015) The landslide problem. J Palaeogeography 4:109-166

Shreve RL (1966) Sherman landslide, Alaska. Science 154:1639-1643

Soukhovitskaya V, Manga M (2006) Martian landslides in Valles Marineris: wet or dry? Icarus 180:348-352

Sowe M, Jaumann R, Neukum G (2011) A comparative study of interior layered deposits on Mars. In: Balme MR et al (eds) Martian geomorphology: Geological Society of London Special Publication, vol 356., pp 281-300

Squyres SW, Grotzinger JP, Arvidson RE, Bell JF 3rd, Calvin W, Christensen PR, Clark BC, Crisp JA, Farrand WH, Herkenhoff KE, Johnson JR, Klingelhöfer G, Knoll AH, McLennan SM, McSween HY Jr, Morris RV, Rice JW Jr, Rieder R, Soderblom LA (2004) In situ evidence for an ancient aqueous environment at Meridiani Planum, Mars. Science 306:1709-1714

Staron L, Lajeunesse E (2009) Understanding how volume affects the mobility of dry debris flows. Geophysical Research Letter 36:L12402

Straub S (2001) Bagnold revisited: implications for the rapid motion of high concentration sediment flows. In: McCaffrey WD, Kneller BC, International Association of Sedimentologists Special Publication (eds) Particulate Gravity Currents, vol 31., pp 91-109

Voellmy A (1955) Uber die Zerstorungskraft von Lawinen. Schweiz Bauzeitung 73:212-285

Warner NH, Sowe M, Gupta S, Dumke A, Goddard K (2013) Fill and spill of giant lakes in the eastern Valles Marineris region of Mars. Geology 41:675-678

Weiss DK, Head JW (2013) Formation of double-layered ejecta craters on Mars: a glacial substrate model. Geophysical Research Letter 40:3819-3824

\section{Submit your manuscript to a SpringerOpen ${ }^{\circ}$ journal and benefit from:}

- Convenient online submission

- Rigorous peer review

- Immediate publication on acceptance

- Open access: articles freely available online

- High visibility within the field

- Retaining the copyright to your article 